Article

\title{
A Framework for Urban Flood Resilience Assessment with Emphasis on Social, Economic and Institutional Dimensions: A Qualitative Study
}

\author{
Behnam Ghasemzadeh ${ }^{1}$, Zahra Sadat Saeideh Zarabadi ${ }^{1, * \mathbb{D}}$, Hamid Majedi ${ }^{1}$, Mostafa Behzadfar ${ }^{2}$ \\ and Ayyoob Sharifi ${ }^{3}$ (I) \\ 1 Department of Art and Architecture, Science and Research Branch, Islamic Azad University, \\ Tehran 1477893856, Iran; behnam.ghasemzadeh@yahoo.com (B.G.); majedi_h@yahoo.com (H.M.) \\ 2 School of Architecture \& Environmental Design, Iran University of Science \& Technology, \\ Tehran 1311416846, Iran; behzadfar@iust.ac.ir \\ 3 Graduate School of Humanities and Social Sciences \& Network for Education and Research on Peace and \\ Sustainability (NERPS), Hiroshima University, Hiroshima 739-8511, Japan; sharifi@hiroshima-u.ac.jp \\ * Correspondence: z.zarabadi@srbiau.ac.ir
}

check for updates

Citation: Ghasemzadeh, B.; Zarabadi, Z.S.S.; Majedi, H.; Behzadfar, M.; Sharifi, A. A Framework for Urban Flood Resilience Assessment with Emphasis on Social, Economic and Institutional Dimensions: A Qualitative Study. Sustainability 2021, 13, 7852.

https://doi.org/10.3390/su13147852

Academic Editor: Beniamino Russo

Received: 10 May 2021

Accepted: 9 July 2021

Published: 14 July 2021

Publisher's Note: MDPI stays neutral with regard to jurisdictional claims in published maps and institutional affiliations.

Copyright: (c) 2021 by the authors. Licensee MDPI, Basel, Switzerland. This article is an open access article distributed under the terms and conditions of the Creative Commons Attribution (CC BY) license (https:/ / creativecommons.org/licenses/by/ $4.0 /)$.

\begin{abstract}
In recent years, the effects of climate change have become more noticeable in Iran, especially in big cities. In particular, climate-related flood risk is increasingly recognized as a potential threat in the capital city of Tehran. Accordingly, the present study aimed to provide a framework/assessment tool to measure Tehran's resilience to flood risks. To this end, 21 professionals from different disciplines were selected through a purposive sampling procedure and were interviewed using semistructured interviews. The analysis procedure resulted in the identification of 3 themes, 15 categories, 40 subcategories, and 235 codes. The themes were social, economic, and organizational; The identified categories were culture and education (since culture is something to be learned through formal and informal education this component has two features: culture and education), participation, trust, attitude, solidarity, resources, empowerment, flexibility, credit, supervision, intercommunication, rules, specialization, and research. Validation of the indicators and their usability based on the opinions of local experts was used to calibrate the assessment tool and ensure its context-sensitivity. The results of this research can help planners and policymakers to increase their awareness of flood resilience. The approach taken in this research may also be useful for developing flood resilience assessment tools in other Iranian cities as well as in other cities of the Global South with similar conditions.
\end{abstract}

Keywords: climate change adaptation; urban resilience; flood resilience; Tehran; resilience assessment

\section{Introduction}

Nowadays, cities are considered the primary human habitat [1]. According to United Nations reports, more than half of the world's population lives in cities, and it is expected that $66 \%$ of the total world population will live in cities by 2050 [2,3]. These settlements are at the mercy of climate change, of which the changes in the hydrological cycle are a prime example [4]. To ensure a sustainable future, urban planning should be properly managed taking into account climate change and increasing urbanization [5]. Climate change is a threat that could have inevitable negative impacts on urban systems and their populations, especially in Asia, with so many megacities [6-9]. Threats and consequences of this phenomenon manifest themselves in various forms such as heatwaves, storms, and floods [10-14]. Proper planning and policymaking are particularly considerableto deal with these complex and wicked problems [15-18]. Flooding is a natural disaster that has caused great damage in Iran and its megacities in recent years [19,20], with 157 cases of flooding recorded in Tehran in five decades (1951-2000), with an increasing trend [21]. 
In the 1950s, 1960s, 1970s, 1980s, and 1990s, 12, 15, 26, 51, and 53 cases of devastating floods were recorded, respectively [22]. For example, the July 1954 flood resulted in the death of about 1500 people and the destruction of the Kan River. In the July 1987 flood, Golabdareh in Tajrish Square and Shariati Street in Tehran were destroyed. In the April 1995 flood, the Kan River was destroyed and five people were killed. Finally, five deaths and significant damage to properties in Sangan, Keshar, and Sulqan villages were reported for the June 2019 flooding in the Kan River, which also destroyed construction operations on the Tehran-North road [23]. In view of increasing urbanization and the effects of climate change, flood risk is increasing worldwide [24,25]. Nowadays, floods are the most recurrent and costly natural disaster in the world in terms of damage [26]. Considering the increased risk of flooding worldwide, the benefits of investing in disaster resilience must be explored [27]. Although floods cannot be prevented, their impact can be greatly reduced by assessing the resilience of vulnerable areas to potential disasters [28-30]. Resilience is a culture-based concept, a response to disasters, and a property of systems [31]. Resilience varies from place to place [32,33]. It is the ability of a system or part of it to absorb, adapt, and recover after the occurrence of disasters [28,34]. Urban resilience is typically defined as the capabilities to increase the tolerance level of cities when disasters occur [35]. Cities should promote resilience to deal with various natural and man-made disasters that threaten their competitiveness, livability, and functionality [36,37]. A resilient city is a stable network of physical systems and human communities, representing how the main activities continue and return to their original state in times of disasters. The most relevant concept of resilience is crisis management and refers to a set of actions taken before, during, and after a disaster to reduce its impacts as much as possible [38-40]. Flood management is a major challenge in view of the increasing number of extreme storms and ongoing urbanization. Therefore, the concept of flood resilience is receiving increasing attention [30]. Various indicators have been offered to assess flood resilience in different cities.

Oladokun and Montz (2019) proposed a conceptual framework for assessing flood resilience in the United States. They explained three dimensions for analysis, including (1) risk absorption capacity, (2) access to resources, and (3) community processes and resource use. Their findings indicated that the proposed framework is an appropriate method for assessing flood resilience, even in the case of limited data availability and relevance [41].

Campbell et al. (2019) also developed a tool to assess flood resilience in large communities. The tool has been piloted in the United States, Peru, Nepal, Mexico, Indonesia, Haiti, Bangladesh, and Afghanistan. This tool contains five dimensions/capitals: (1) social capital, (2) physical capital, (3) natural capital, (4) human capital, and (5) financial capital [42].

Similarly, Tyler and Moench (2012) designed a framework for urban climate resilience. They examined and demonstrated how the general theory of urban climate resilience can be developed for planners in an operational framework. They explored these concepts and theories across a wide range of domains. This framework combined theoretical and empirical knowledge of the factors contributing to resilience. This framework also included characteristics of urban systems, factors related to these systems and their management, institutions that link systems and factors, and patterns of climate change. This urban climate resilience framework was shown to facilitate climate adaptation planning in cities and went beyond a focus on climate impacts to integrate environmental, infrastructural, social, and organizational resilience factors [9].

Moghadaset al. (2019) also evaluated Tehran's resilience to flooding using a multicriteria system (combined AHP-TOPSIS). In this study, the resilience assessment focused on its intrinsic characteristics and capacities in the area of flooding caused by surface water or river overflow. This method was a combination of AHP for prioritizing the selected indicators and the TOPSIS tool for ranking different areas of Tehran based on their resilience. The evaluation indicators of this research consisted of six social, economic, institutional, infrastructural, environmental, and local dimensions [43].

A review of the related literature showed that various studies on flood resilience had been conducted using different indicators depending on the target area. Based on the 
results, the selected assessment indicators were different in different cities and regions. Indicators derived from underlying characteristics, on the other hand, played a less considerablerole. Little has been done to identify and develop new contextual indicators and criteria. Moreover, no comprehensive research has ever identified these indicators in Iran. Therefore, this qualitative study sought to explore the issue of flood resilience in Tehran for the benefit of policymakers, planners, and decision-makers. Considering Tehran's characteristics, such as its geographical location, social, institutional, and economic conditions, and infrastructural and superstructural weaknesses, a detailed analysis is required to identify appropriate assessment indicators for this megapolis. Against this backdrop, this study aimed to identify and introduce indicators for assessing the degree of flood resilience in Tehran from the perspective of experts using the qualitative content analysis approach.

\section{Materials and Methods}

\subsection{Study Area}

With an area of 730 square kilometers, Tehran is located between $35^{\circ}$ and $34^{\prime}$ to $35^{\circ}$ and $59^{\prime}$ Nand $51^{\circ}$ and $5^{\prime}$ to $51^{\circ}$ and $53^{\prime}$ E (see Figure 1). The metropolis is located on the southern slope of the central Alborz Mountains and in the middle of the northern and southern areas. Its relatively high altitude from the sea level, the difference in altitude in its different zones, its expansion to an altitude of $2200 \mathrm{~m}$, and its use of waterways and canals increase the risk of flooding in Tehran [44,45]. The geomorphology of the city exposes it to the risk of flooding [46,47].

Participants were selected through internet profile searches and previous acquaintance of researchers. After contacting them, prior arrangements were made by telephone and email communications for an interview. Due to previous arrangements with the participants, all interviews were conducted in one session and there were no interviews that were left incomplete or conducted in several sessions. On average, each interview took one hour and $15 \mathrm{~min}$. Participants were not given any special rewards or privileges for conducting the interview, but they participated in the research with enthusiasm, individual desire, and because of their common concerns. In order to gather comprehensive information on the three dimensions of resilience, related specializations were considered in the selection of participants and continued until the achievement of theoretical saturation. The interviews were conducted in person and by appointment by phone and email. The interview questions were designed as semi-structured questions. After an introductory explanation by the researchers, the first interview question was: "How significantis resilience as an expert in your field and why?". A main part of the questions was formed during the interview and the information exchanged between the researchers and the participants. 


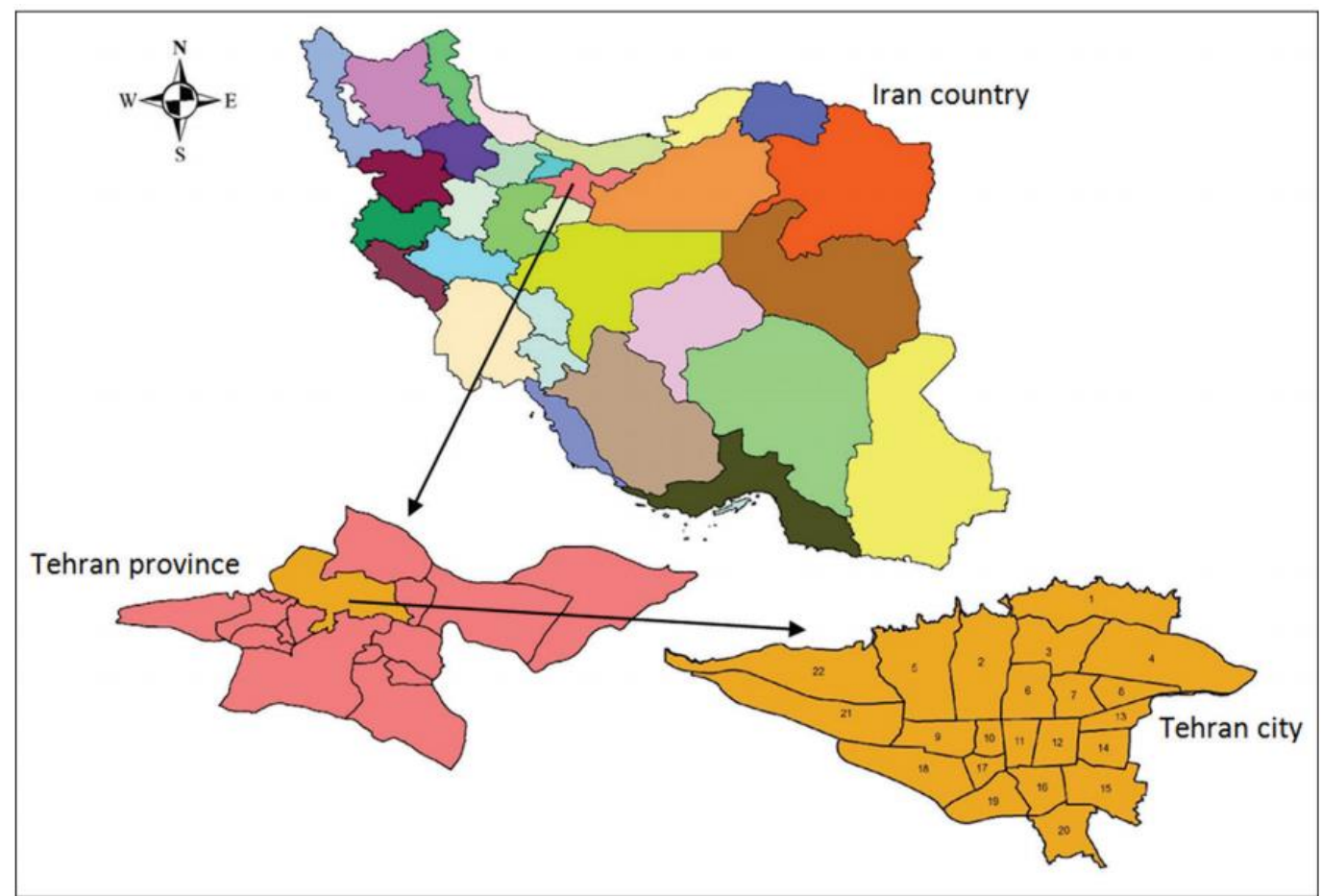

Figure 1. Map of the city of Tehran in the Tehran province, Iran [48].

\subsection{Study Design}

This paper is part of a larger research project to propose a tool for evaluating Tehran's resilience to flooding. The project was registered at Islamic Azad University, Science and Research Branch, in 2019. In this study, the conventional content analysis approach was used. The required data were collected directly from the participants without imposing predefined themes or personal views [49,50]. Data were collected by interview and analyzed by the association of meanings, with no role for pre-existing theories [51]. The knowledge obtained was thus based on the unique perspectives of the participants and from real textual data. Then, the codes and themes were inductively extracted from the raw data [52].

\subsection{Participants}

The participants of the study were 21 individuals (fifteen males and six females), including experts who had experience in urban flood resilience. Their age ranged from 35 to 59 , and they had 3 to 15 years of professional experience. Table 1 shows the demographic characteristics of the study participants.

Table 1. Demographic characteristics of the participants $(n=21)$.

\begin{tabular}{ccc}
\hline Demographics & Categories & n (\%) \\
\hline \multirow{2}{*}{ Gender } & Female & 6 \\
& Male & 15 \\
\hline \multirow{2}{*}{ Age } & $30-40$ & 4 \\
& $40-50$ & 12 \\
Years of Professional Experience & $\geq 51$ & 5 \\
\hline \multirow{2}{*}{ Education Level } & $<10$ & 15 \\
& $10-20$ & 6 \\
\hline \multirow{2}{*}{$*$} & Master's degree & 10 \\
& Doctorate degree & 11 \\
\hline
\end{tabular}


Purposive sampling with a maximum variance of age, gender, occupation, educational level, and work experience was used to obtain comprehensive information.

Table 1 provides a brief profile of the characteristics of the participants so that the readers have a basic understanding of the interview conditions and the selection of the interviewees, as this information can help deepen the findings and better evaluate the present writing.

Data generation continued until data saturation was reached $[53,54]$. Benchmarks for selecting participants were studying floods or urban resilience in Tehran, willingness to participate, and professional experience in flood disaster management.

\subsection{Data Analysis}

The content analysis method was used for data analysis. The process of data analysis followed the steps suggested by Graneheim and Lundman [55], which include (1) transcribing the interviews and reviewing them several times to obtain a correct understanding of the whole text, (2) extracting unique elements and preparing initial categories, (3) finalizing the categorization and assigning appropriate labels to each category, (4) arranging subthemes based on their similarities and differences, and (5) selecting appropriate names for themes to capture the content of each theme. We have now clarified that data analysis was conducted manually.

\subsection{Rigor and Credibility of Data}

To increase the rigor of the data collected, Guba and Linklen's four measures were used: credibility, dependability, transferability, and conformability [56-61]. The researchers also used other measures to increase the credibility of the data. These included engaging with the data for three months and spending sufficient time on data collection and analysis. Member checking was used to increase the dependability of the dataso that participants themselves were asked to rate the degree of dependability. Transferability refers to the applicability of the study findings and means that the results can be transferred to and applied in other settings or similar groups. The researchers also provided rich descriptions about the context and participants, as well as a clear description of the barriers and limitations of the study to enhance the applicability of the study findings in other social contexts. Finally, to enhance the confirmability of the study, all steps of the study, especially the data analysis, were recorded with details so that another researcher who wishes to continue the research can follow the study by simply following the notes about the interviews, analysis, and other steps of the study.

\section{Results}

The analysis of the data revealed 3 themes, 15 categories, 40 subcategories, and 235 codes. The themes identified were social, economic, and institutional. The categories also included culture and education, participation, trust, attitude, solidarity, sources, empowerment, flexibility, credits, supervision, intercommunication, rules, specialization, education and organizational culture, and research.

\subsection{The First Theme: Social}

The social approach aimed to identify, analyze, and evaluate the social potential opportunities about Tehran's resilience to environmental crises and natural disasters. Given this, social theme was regarded as an influential issue from the participants' view.

According to the participants' views, the social theme has six categories of "culture and education", "participation", "trust", "attitude", "solidarity", and "resources". They believed that culture and the promotion of general awareness in society can be influential in promoting the constructive interrelationship of society and the environment, which in turn increases the resilience of society against natural disasters.

The precondition of "culture and education" is the existence of appropriate programs that inform the right ways of exposure to and management of floods. Thus, it is essential 
to produce and perform cultural-educational programs for citizens. In line with this, one of the participants stated that "citizens need to receive information and consultation from experts". Moreover, the existence of counseling centers can be influential in meeting these needs. The point to mention, however, is that mere performance of educational programs without attention to their content will not be that effective. Hence, producing programs with suitable content for social media, as new communication tools, can play a key role in culture and education. According to one of the participants, "nowadays, virtual space has high capacities to informing and increasing people's awareness in critical situations such as floods. Therefore, appropriate content should be produced for it".

Participants also cited rumors and post-disaster stress as factors influencing resilience. Therefore, rapid disaster management can prevent these rumors and stresses. In accordance with this, one of the participants contended that "citizens should be continuously informed of measures and events. Officials should use facilities such as radio, TV, and virtual channels to give precise and quick information to people".

Using "social communication networks" can substantially improve the interaction of people and officialsand could also speed up the chain of events. This, however, requires that officials have a correct understanding of the culture and social relations of citizens. One of the participants rightly asserted that "policy makers and decision makers should be thoroughly familiar with different local culture and beliefs of society to be able to make correct decisions in critical situations". Training is one of the main criteria proposed by the participants with regard to the issue of "appropriacy of educational programs" with social conditions; one of the participants maintained that "educational programs should be in line with the audiences' conditions and traits. For example, the age groups traits should be taken into account. Their education level is also principal. Other factors such as gender, ethnicity, social class, job, religion, skills level, etc. also merit attention".

"Participation", as one facet of social capital, is one of the most powerful and available sources at the time of disasters. This category in itself entails two subcategories: "citizens' responsibility before and after flood" and "citizens' and people-based institutions" participation with organizations".

Regarding the subcategory of "citizens' responsibility before and after flood", one of the participants stated that "community forces are available at time of disaster. Thus, if they can be effectively organized, they have high potential to deal with the disasters effectively".

According to the participants, people-oriented organizations play a seminal role in creating constructive interactions between citizens and officials in times of crisis. More specifically, one of the participants remarked that "having active people-based groups and organizations has role in enhancing the positive effective interrelationship of people and officials which, in turn, increase the effectiveness of programs related to crisis management".

The participants also believed that "citizens' trust in supportive institutions" and "citizens' trust in officials' programs and policies" are factors for better management of critical situations. In accordance with this, one of the participants stated that "citizens should be confident that supportive programs by government and related organizations are effective enough to deal with crises". Similarly, one participant asserted that "sometimes, lack of trust to institutional programs and measures can discourage them about the outcomes of actions and it may cause citizens to prevent from cooperation with the officials".

The present study revealed that attitude-related factors play a key role at the time of exposure to natural disasters such as floods. This issue was categorized with two sub-categories of "attitudes and beliefs of citizens toward factors and consequences" and "citizens' satisfaction". Attitudes are a series of common sense beliefs that can affect the behavior of citizens in the face of disasters; for example, when a person considers the occurrence of floods as the result of human sins and considers them subject to divine punishment and believes that God wants to punish rebellious and sinful people through floods or wash away their sins so that they can start a new life free from sin. 
A part of cities' social resilience to risk is related to citizens' cultural attitudes and beliefs. Fatalistic beliefs in inevitable destiny in Iranian culture and tradition might hinder Iranian people from accepting scientific measures. Although fatalistic beliefs reduce the tolerance of people after the disaster, these beliefs make people not think much about prevention and preparedness before disasters. For example, one of the participants stated that "some of unscientific and traditional beliefs such [as] inevitable destiny especially in small societies can prevent people from reaching correct understanding about crises and ways of dealing with them". Given this, it can be asserted that a lack of such attitudes and beliefs in society can make us hopeful for more effective participation of social forces and citizens in times of crisis.

Promoting citizens' attitude is closely related to their objective and subjective evaluations. They will have more active participation in crisis management when they have enough satisfaction from the officials' measures. Table 2 shows satisfaction criteria from the participants' viewpoints. One of the criteria is the participation of community institutions, which can significantly promote the citizens' attitude. As an example, one of the participants contended that "participation of community institutions can help to promote the attitude of citizens about critical situations".

Social solidarity is another factor in social resilience. "Solidarity" involves two subcategories of "place attachment" and "readiness and communication actions of citizens and areas". Place attachment is one of the factors that generates solidarity. In line with this, one of the participants said that "at time of crises, if citizens feel attached to their dwelling place, more solidarity is created".

Creating cultural and social relations between citizens can be effective in maintaining their cohesion. More specifically, one of the participants stated that "staying loyal to ethnic and cultural norms can greatly help to make a constructive interaction among citizens as these norms have potential capacity to create social solidarity provided that they are used correctly".

The resilience of communities against crises is largely dependent on the available sources. Sources such as "health and hygiene resources", "social resources", "mental resources", "communication resources", "institutional resources", and "area safety" can lead to strong social resilience against floods.

Sources mean capacities and potential and actual opportunities that can be used for improvement of affairs. One of the participants said that "the degree of access to medical facilities and equipment at time of disasters is related to manage the situation". Another participant stated that "creating and developing NGOs and civil institutions can help to make social capital to improve critical conditions". In accordance with the need for psychological resources, one participant asserted that "officials should promote life expectancy among citizens by using their previous experiences. This can make them resilient psychologically". In addition, citizens should have necessary access to information resources. One of the participants rightly stated that "the more the local information resources, the better the process of crisis management".

"Institutional resources" should also have the capacity to cover all the victims. In line with this, one participant said that "programs that are organized to mitigate risks of crises can be more effective only when they have the capacity of covering more population". Furthermore, appropriate and safe spots in the area should be determined to be used for reaching a stable situation. For example, regarding the issue of "area safety", one of the participants asserted that "after disasters such as destructive floods, if citizens have access to safe places, the negative effects of the disaster will be fewer and the disasters can be managed better". Table 2 presents the components of social theme. 
Table 2. Social Theme.

Category Sub-Category

Producing and performing educational-cum-cultural programs for citizens

Informing citizens

Culture and Education

Capacity of social relations networks

Citizens' responsibility before and after a flood

Appropriacy of educational programs

\section{Code}

Compiling and publishing books

Preparing and publishing educational brochures

Producing and publishing short educational notes Establishing counseling centers

Compiling and providing educational content for virtual spaces Running educational workshops

Informing the citizens of disasters and furniture insurance and unemployment insurance

Existence of valid communication channels between citizens and officials

Citizens' awareness of correct behavior at time of disaster

Installing warning and informing signs in risky spots

Holding cultural festivals related to floods such as photography

and painting in cultural spaces and centers of the prone places Informing citizens of vulnerable spots and areas

Attention to local citizens' culture and beliefs in decision-making processes related to floods

Prioritizing social networks to promote citizens' awareness of flood terms

Using locals' experiences

Using local public places (mosques/culture houses/religious places) for informing purposes

Appropriacy of educational and skill programs with differen

ages, ethnicities, educational, social class, job, and religious groups

Time suitability of educational programs

Cooperation with supportive organizations such as fire-fighting and Red Crescent

Calling for and organizing local forces Educating and training forces

Supporting, helping, and moving damaged people to safe places

Citizens' and people-based institutions' participation with organizations

Participation

Trust

Citizens' trust in officials' programs and policies
Citizens' trust in supportive institutions
Participation in planning

Activating civil institutions

Using community capacities such as religious places for planning and performing operations

Citizens' brainstorming in organizational measures

Making use of benevolent persons and charity institutions

Participation of women and youths

Providing needed facilities and equipment

Investment for promoting well-being level
Insurance organizations

Government support programs

Banks and financial institutions to compensate for damages

Trust in related organizations such as crisis management,

police, Red Crescent, etc.

Formal statistics and reports

Public organizations

Organizational programs and actions

Media regarding reflection of city environmental risks

Extant capacity and amenities

Expertise and knowledge 
Table 2. Cont.

Category Sub-Category

Attitudes and beliefs of citizens toward factors and consequences

Attitude

Citizens' satisfaction

Place attachment
Solidarity Readiness and communication actions of districts
and citizens

\section{Code}

Attitude towards and belief in the probability of flood Lack of fatalism

General understanding of the sensitivity of situations Learning from experience

Tendency to leave vulnerable and prone areas Sensitivity to measures that lead to risks Local understanding of danger

Following rules and instructions, for example about construction standards, to head off crises Prevailing moral and cultural values

Programs and services pertinent to identification of vulnerable groups

Programs and services related to local evacuation

Facilities and equipment

Officials' behavior

Informing the public in a timely and correct manner Timely measures by officials

Supportive aid

Attention to the needs of the people

Local council assistants

City councils

\section{Place identity}

Place vitality

Place dependence

Place commitment and loyalty

Social attachment

Keeping citizenship relations before during and after disaster Responding to aid needs and fast evacuation of citizens at time of flood

Citizens' readiness for fast evacuation Maintaining and strengthening public morale

Ethnic and cultural prejudices Public trust

Quality of kinship and family interactions Intergenerational ties Face-to-face interactions

\section{Food resources}

Drug resources

Medical facilities

Health and hygine resources
Hygienic infrastructures such as hospitals and clinics Hygiene-related resources such as physicians and nurses

Physical and mental health of citizens Rehabilitation services 
Table 2. Cont.

Category Sub-Category

Code

Native population

Development of civil organizations

Less vulnerable populations such as elderly

people, children, infants, and disabled ones

Lack of ethnic and racial minorities

Low immigrant population

Low cases of divorce Education

Few legal cases

The population belonging to the middle and upper classes

Social resources

Population having access to housing

Equal access to public transportation Access to law consultants

Children and elderly care centers

Suitable educational facilities

Suitable resources to move disabled people

Active population (15-64)

Women employment

The power of fast voluntary reactions

Citizens covered by social security and medical services and health insurances

Diversity of knowledge and expertise of citizens

Balanced population distribution

Cultural diversity

Religious ties

Social ties between tribes and relatives Peace and security in society Educational justice

\begin{tabular}{|c|c|}
\hline Mental resources & $\begin{array}{c}\text { Citizens' psychological calmness during and after } \\
\text { the disaster } \\
\text { Encouraging a passion for life in the affected areas } \\
\text { by officials drawing on their previous experiences } \\
\text { Psychological counseling centers } \\
\text { Mental health services }\end{array}$ \\
\hline Communication resources & $\begin{array}{c}\text { Citizens' communication skills (fast } \\
\text { communication and expansion of relations) } \\
\text { Presence and diversity of local media } \\
\text { Presence and diversity of online/virtual media } \\
\text { Language proficiency } \\
\text { Sociability }\end{array}$ \\
\hline Institutional resources & $\begin{array}{c}\text { Skilled and specialized population } \\
\text { Continuous compensation for damages based on } \\
\text { rebuilding progress } \\
\text { Motivators by municipality and city council } \\
\text { volition for owners in line with compatibility } \\
\text { measures } \\
\text { Budget dedication to educate citizens } \\
\text { Population working in emergency services } \\
\text { Covered population in risk mitigation programs }\end{array}$ \\
\hline Area safety & $\begin{array}{l}\text { Citizens' access to safe spots } \\
\text { Population dwelling in safe zones }\end{array}$ \\
\hline
\end{tabular}

\subsection{The Second Theme: Economic}

According to the participants, economic capabilities can be divided into three categories: "empowerment", "flexibility", and "credits". "Empowerment", which can be divided into two subcategories of "citizens' financial capability" and "active economy", indicates the citizens' economic capacity for resilience against floods and other natural disasters.

"Citizens' financial capability" is an economic element to manage crises. According to one of the participants, "if citizens have high financial capabilities, they can adapt 
themselves with critical conditions better. For example, if their properties stay safe from damage, they can help others to return to desirable conditions and adapt to the situation".

"Citizens' financial capability" is closely related to presence of dynamic economic resources and "active economy". In line with this, one of the participants stated that "economic dynamics in the area largely depends on factors such as existence of active big and small industries as well as service and productive corporations that can make citizens powerful economically against disasters".

One of the participants rightly stated that "if different groups of society have equal decision making power, their reactions at time of crises will be more effective".

Economy can be resistant against crises only when it has the "flexibility" capability. In the participants' views, this capability can be achieved by the "ability to return to employment and income conditions", "financial-credit supports", and "insurances performance".

"Flexibility" means improvement and corrections of the area economy and plays a key role in rebalancing and resilience against crises. One of the participants expressed that "after any disaster, it is essential to return to normal conditions. Specifically, improvement and reopening of jobs and shopping centers can both help to return the macro-level economy of the society and increase the adaptability of citizens". "Financial-credit supports" are also determinant. According to one of the participants, "organizations and institutions that are responsible for crisis management need to have enough budget and equipment to be able to fulfill their duties effectively". Another participant hinted at the role of "insurances performance", saying that "if insurances have adequate efficiency and power, it can be expected to improve the conditions sooner". Similarly, another participant stated that "insurances are of great importance to support the suffered people and their effective performance can substantially help to return the damaged people and institutions to normal conditions".

Since organizations that are in charge of crisis management-such as fire stations, emergency services, welfare services, etc.-do not have predictable budgets, they often lament about the shortage of credits and budget that negatively influences their performance. Allocating enough of a budget can help organizations purchase suitable equipment and facilities which, in turn, enables them to perform more effectively at the time of disasters. According to the participants, "credits", which incorporates two subcategories of "supplying necessary facilities for responsible organizations" and "specific budget for research", is another factor. For example, one of them expressed that "the budget that is allotted to responsible organizations should be proportionate to their duties. Often, this budget is not enough". Another participant contended that "holding conventions and seminars can greatly help to publish information and increase knowledge of related managers and staff. Thus, sufficient budget should also be dedicated to these kinds of seminars". Table 3 shows the economic facet structure. 
Table 3. Economic Theme.

Category Sub-Category Code

Income level

Financial resources status

Properties status

Citizens'financial capabilities

Goods and services price

Area economic balance

Low Gini coefficient

Low poverty rate

Active stores and shopping centers

Diversity of jobs and livelihood methods

Development of employment opportunities in cities (big and small industries/production and service-giving corporations)

Business opportunities

Continuous promotion of production capacities

Internal investment

Empowerment

Employment of local forces

Link to the regional economy

Economic cooperation with other countries

Active economy

Private and public sector participation in local businesses

Financial stability and flexibility

Economic self-sufficiency

Distribution of employment opportunities and industries in different regions

Internal gross production

Development of economic structures (shopping

centers/rules/economic ties)

Sustainable employment

Sustainable employment of municipalities

Employed population

Expansion of non-urban production conditions (active agriculture/fertile lands)

Production, supply, and consumption chains

Exploiting tourism capacities

Appropriate tax incomes

Appropriate economic networks

$$
\text { Reopening of jobs }
$$

Power of reopening educational centers

Ability to return to employment and income conditions

Flexibility

Financial aid/credit supports
Power of reopening buying and selling centers

Compensation for vulnerable businesses Re-booming of markets

Prevention from work force reduction

Flexibility of local businesses and economies

Proportion of organizations' budget to their duties Attention/economiclivelihood aids to vulnerable people Bestowing low-interest loans

Financial supply for developing urban infrastructures Subsidies and non-cash supports

Insurance organizations' supports Unemployment insurance performance

Insurance performance Insurance of land use

Accountability of relevant officials

Crisis management budget share Bank facilities' conditions

Credits
Holding seminars and conventions Research and development

Specific budget for research

\subsection{The Third Theme: Institutional}

Based on the participants' attitudes, the institutional theme entails seven categories: "regulation", "intercommunication", "rules", "specialization", "education and organizational culture", and "research". The "regulation" facet, in itself, incorporates two subcategories of "continuous review of urban rules" and "supervising the responsibles' measures by regulatory institutions". 
For example, one of the participants stated that "the extant rules might not be effective at present conditions and do not adapt with social, economic, and place conditions. Thus, they should be revised and modified".

Monitoring the performance of agents is also determinant in that it can help to evaluate their actions by comparing the performed measures. Accordingly, one of the participants expressed that "each of the defined responsibilities in crises management should be given specific ID and code so that they can be easily assessed".

In a time of disaster, different organizations play different roles. It is often observed that their duties are not clear enough, which causes interference and ambiguity among staff. Therefore, "intercommunication"-with its four subcategories of "cooperation of relevant organizations in planning and research", "maintaining reliability and continuity of services provided by organizations", "cooperation of officials and executives with public groups and local businesses", and "collaboration to facilitate law enforcement" - has been identified as a factor of resilience.

Joint cooperation of institutions can have varying aspects, one of which is planning and research. This cannot be achieved unless the responsibilities and roles of different staff members are clearly pinpointed by holding primary meetings and sessions. In line with this, one of the participants contended that "using the knowledge and experience of experts requires meetings with scholars and experts".

Cooperation among different organizations and units can be achieved by analyzing the strong and weak points of previous experiences and preparing a guideline for future cooperation. One of the participants rightly pointed out that "the more the cooperation and interaction among responsible groups, the more their efficiency and effectiveness".

On the impact of interactions between related organizations, one of the participants believed that "in order to support local businesses and to prepare them to effectively deal with crises, planning special policies and programs in this regard is vital". The participants also believed that constructive interaction of the responsible groups should facilitate law enforcement. For example, one of the participants stated that "sometimes, there are strict and effective rules to deal with and prevent floods. However, these rules become useless as a result of lack of collaboration among different groups and units. Thus, cooperation and collaboration among organizations is essential to prevent flood". In general, despite the presence of sound regulation, its efficiency might reduce due to lack of collaboration among responsible organizations and units.

Participants also identified "rules" as another category of resilience which entails two sub-categories of "capacity" and "power". The "capacity" of rules includes different issues such as "transparency", "comprehensiveness", "inclusive", and "balance" to cover all relevant officials' and managers' needs. Transparent rules enhance managers' innovation ability and pave the way for better interactions with other groups and units. Additionally, the "comprehensiveness" of rules can neutralize any ambiguity in activists' measures. One of the participants similarly stated that "in some cases, defect in rules and lack of comprehensiveness of rules make the officials perplexed to take effective immediate decisions".

"Power" of rules and regulation refers to their enforcement ability and efficiency to manage crises. Regarding this, the participants pointed to the sub-categories of "efficiency" and "executive guarantee". They believed that rules should not only be efficient enough to respond to the stakeholders' needs, but also have necessary executive guarantees for applicability. To be more specific, one of the participants expressed that "rules are often only on paper and there are many hurdles for them to be executed thoroughly".

The participants of this study pointed to "specialization" with two sub-categories of "management and executive ability" and "awareness and belief of managers and decision makers". Non-specialized managers in executive and headquarters sections often have experimental training and learn methods and techniques of crisis management through trial and error. In addition, in general, one criterion to manage crises such as floods is making use of management and executive abilities of specialized and capable managers. 
In accordance with this, one of the participants stated that "the degree of expertise of managers and officials to deal with disasters and crises tightly bounds with their level of skill and experience".

"Degree of skill of managers and officials for flood management", "determining and forming flood disaster management committee with high interdisciplinary technicalacademic knowledge", and "degree of managers' and decision makers' beliefs in watershed management" are other factors mentioned by the participants in this regard. One of them expressed that "to better manage floods, there should be formed a committee with experienced and knowledgeable members".

Needless to say, without "education and organizational culture", the application of "educational-cum-cultural programs", and the "promotion of informing culture, informing and sharing information", organizations cannot achieve much. The participants of the study have also referred to these issues, as well. One of the participants, for instance, asserted that "a part of the managers' responsibilities and duties is dependent on the way they interact with society. Managers, then, should have complete knowledge and understanding regarding psychological management strategies which can be fulfilled by running appropriate educational programs". Other strategies that have been identified by the participants within the category of "promotion of informing culture, informing and sharing information" are "tendency of related organizations to educate and inform citizens", "tendency to innovation in institutions", "culture of information sharing in society", "culture of organizational informing", "presence of a specific system/institution to manage public thoughts and deal with psychological operations", "unity of procedure in informing", and "culture of cooperation". In line with this, one of the participants stated that "in our organization, people work only within their own duties and lack of cooperation culture hinders them from using each other's capacities".

According to the viewpoints of the participants, the capability of organizations and institutions to manage crises such as floods is largely dependent on their ability in research activities. Research in itself incorporates three subcategories of "supportive framework", "sharing knowledge and information between scientific and organizational centers", and "experiencing".

Institutional and material support is principal for research. For example, one of the participants explained the issue of "supportive framework" as follows: "Organizations responsible for crisis management should have a clear program to conduct research and update their knowledge about crisis management".

Utilizing the information of other organizations will be very effective in organizational research. One of the participants pointed out that "academic centers need reliable data and information for better analysis of affairs related to crises. These kinds of information should be provided for them by related organizations". More specifically, one of the participants expressed that "the experience of managers who have already acted successfully at time of crises should be used". Table 4 presents the structure of institutional theme. 
Table 4. Institutional Theme.

Category Sub-Category Code

Continuous review of urban rules

Regulation

Supervising the responsibilities and measures by regulatory institutions
Continuous survey of rules' strengths and weaknesses Adaptation of rules with upstream documents

Adaptation of rules with time conditions, social, place, and environmental needs

Controlling (programs and plans) illegal development Using measures of punishment and protection

Supervising the rebuilding process of damaged regions Suitable supervisory structure to assess measures

Assigning responsibility IDs for officials of crisis management

Feasibility of approved programs about management and exposure

Supervision and assessment of pollution clearing after flood Obligation to enforce disaster insurance

Participation of scientific parks and academic centers

Holding specialized sittings (experience exchange) with international experts and academic professors Attention to participatory planning

$$
\text { and research }
$$

Interorganizational coordination

Coordination of rules in different units and sections Joint organizational interactions

Intercommunication Maintaining reliability and continuity of services provided by organizations

Technical and organic work distribution among organizations Continuity of organizational programs

Cooperation of officials and executives with public groups and local businesses

Cooperation of executors and officials with elites and public groups

Taking adaptive policies for local businesses and economy

Participation of local institutions and government to supply insurance financial portion

Collaboration to facilitate law enforcement

Cooperation of organizations to facilitate rules Inter-institutional cooperation to prevent occurrence
Rules

Capacity

Power

Management and executive ability

Specialization

Awareness and belief of managers and decision makers

Educational-cum-cultural programs

Education and organizational culture

Transparency
Comprehensiveness
Inclusive
Balance
Efficiency
Executive guarantee

Specialized local decision makers and policy makers Specialized managers and executors and personnel at macro-level

Awareness of management strategies and urban watershed management Leadership power

Job skills of managers and responsibleauthorities formation of crisis management committee with experienced and academic members

Belief in management and exposure strategies such as watershed science

Holding disciplined preparation maneuvers in the organizations

Compiling educational content of standards

Running educational programs for citizens

Compiling and running educational programs about mental-social strategies

Holding educational workshops

Holding joint meetings to share new scientific findings Individual, collective, and organizational learning capacity

Tendency of related organizations to educate and inform citizens

Tendency to innovation in institutions

Culture of information sharing in society

Culture of organizational informing

Presence of a specific system/institution to manage public

thoughts and deal with psychological operations

Unity of procedure in informing 
Table 4. Cont.

\begin{tabular}{|c|c|c|}
\hline Category & Sub-Category & Code \\
\hline \multirow{3}{*}{ Research } & Supporting framework & $\begin{array}{c}\text { Research need assessment } \\
\text { Compiling a comprehensive program to follow research results } \\
\text { until obtaining results } \\
\text { Pinpointing research program frameworks }\end{array}$ \\
\hline & $\begin{array}{l}\text { Sharing knowledge and information between } \\
\text { scientific and organizational centers }\end{array}$ & $\begin{array}{c}\text { Data, statistics, and data base } \\
\text { Geographic information system } \\
\text { Strengthening academic and scientific centers } \\
\text { Providing basic information and facilitating requests from } \\
\text { scientific centers }\end{array}$ \\
\hline & Experiencing & $\begin{array}{l}\text { Recording the history of flood events } \\
\text { Using the experience of successful countries in dealing with } \\
\text { floods } \\
\text { Adapting programs to circumstances } \\
\text { Inviting experienced managers and activists to draw on their } \\
\text { experience }\end{array}$ \\
\hline
\end{tabular}

\section{Discussion}

Paying attention to the social, economic, and institutional dimensions of resilience is a very complex task because these dimensions are intertwined. In fact, many of the concepts used in the present study are not easily distinguishable in practice. Therefore, the classification of concepts into three categories of social, economic, and institutional is usefulto understand them from a theoretical point of view and to identify the not-so-clear boundaries of these dimensions. Therefore, the classification presented may be challenged by some researchers and scholars or may not be in complete agreement with some other classifications in the existing literature. However, in addition to emphasizing the important points, an attempt has been made to make the correct division based on their comparison with the existing literature so that in practice, it can be used as an analytical tool to explain the issue of urban resilience and gather the required information.

In the social approach, the nature of the relationship of people and society with the environment and ecosystem was considered [62-65]. In this approach, various factors such as human actions, social structures and capacities, cultural contexts of society, and ideology that can pave the way for continuous exploitation of the environment are discussed to define the nature of this relationship.

Considering social aspects such as population growth, presence of deteriorating urban structures, multicultural character and structure of social classes, marginalization, speed of geographical expansion, suburban cities and industries, and problems related to urban life, Tehran has always been identified as factor of environmental degradation, and consequently, its vulnerability to natural disasters has been considered high $[66,67]$. Thus, it has been a case to study in social and environmental fields [68-71]. It seems that improving the behavioral patterns and lifestyle of its citizens can help to increase its adaptation capacity after natural disasters such as floods. Culture and education constitutean ongoing process which should be started from the beginning stages of socialization through schools and families [72-76]. Counseling centers and workshop educational programs can also be effective during and after crises [3,77-81].

Rumors and stress related to a disaster might negatively affect the service-giving process [82-84]. Therefore, quick and precise information-giving should be performed at the time of a flood. Similarly, on-time and correct management of information before, during, and after the disaster, along with suitable education through valid communication channels between citizens and officials, can substantially mitigate its negative consequences [85-88].

Given its excessive immigration in recent decades, Tehran has turned into a multicultural megacity [89-92]. Hence, paying attention to its different cultural dimensions in times of disaster is highly determinant. 
Education is dynamic and flexible, meaning that its efficiency is dependent on the time, place, conditions, audiences, and general needs of the target society [35]. Education in times of disaster is of greater importance in that in these situations, education should happen sooner and the results should become clear faster [79].Training can be started immediately after the rescue operation and temporary accommodation of the injured; for example, training regarding cold and heat care, animal care, health care, and how to interact with government agencies to provide assistance, etc. Since a significant portion of the residents of Tehran's vulnerable areas have low social skills and academic qualifications, attempts to increase their awareness and information can do much to improve social resilience. Tehran's citizens should have up-to-date and adequate information on how to deal with flood disasters, and should also be aware of the support organizations they can turn to for help in times of disaster. Both citizens' individuals' skills and their interaction networks are key to effectively manage risks and crises, as these skills can be used not only to help victims but also as a way of education and knowledge transfer. Social relationship networks have a high potential to transfer local knowledge.

To manage and monitor the damages of natural crises such as floods, taking correct actions is of great importance. It is apparent that most crises are highly unpredictable and related organizations and officials are unable to take immediate measures. Using social capitals can compensate for this weakness. Since citizens have immediate access to damaged locations and are adequately familiar with the location conditions, they can play a key role in managing crises [93-97]. Citizens' participation can make it faster and easier to provide necessary equipment and facilities and organize social forces.

Social capital has institutional capacities, group and voluntary participation within civil groups that can play their role in times of disaster individually or collectively. If organized in people-based groups properly, social capital efficiency can markedly increase [98-100].

Trust is a facet of social capital in times of disaster as it can significantly improve the formation of positive interactions among citizens and civil organizations [101,102]. Trust in supportive institutions such as insurance companies can play a seminal role in mitigating stress and economic and social pressures in critical conditions [101]. Trust in supportive institutions means intrinsic security of citizens [103] and if citizens feel such security, they are likely to show appropriate behaviors in times of disaster. This, in turn, makes it easier for the pertinent organizations and officials to better monitor crises [104].

Attitudes and objective and subjective evaluations are among environment phenomena, and many human behaviors are a reflection of attitudes and evaluations in different situations [105-107]. Further, attitude is tightly related to history, culture, and social and environmental factors $[108,109]$. Since Tehran is a multicultural city, paying attention to cultural elements in urban planning to achieve resilience is more complex than in other cities, especially because a large part of Tehran's population is made up of immigrants who are still following their local traditions.Kinds of human attitudes are relevant in determining actions, priorities, and values. Thus, attitude helps people to select their behaviors in varying situations. In critical situations such as floods, although many people's actions and behaviors are affected by emotions and immediate reactions, their deep cultural beliefs and mental subjective evaluations can be determining factors in the kinds of actions they show. Attitudes such as fatalistic beliefs, while they may increase endurance in the face of adversity, prevent foresight, anticipation, and appropriate measures to deal with risks. Fatalism believes that all events are beyond human control [110].

Acevedo [111] considers religion and culture to be effective in shaping fateful thoughts in Islamic societies about disasters such as earthquakes and floods because they consider them as the will of God. In Morocco, for example, low-educated people consider earthquakes to be a divine will. They think that God protects good people from disasters [112]. Fatalistic attitudes prevent people from being prepared for dangers [113,114]. In this study, when the people of Agadir were asked, "Like the earthquake of 1960, will Agadir ever be hit with another big quake?", 75\% of those with less than 8 years of education chose 
the option, "I will never say what only Allah says"; less than $25 \%$ of those over the age of 12 chose this option. More than $75 \%$ of those with more than 12 years of education chose the "yes, of course" option, compared to less than $25 \%$ of those with less than 8 years of education [112].

Social solidarity, which is measured by the cultural and social distance of social groups, refers to a joint interaction among social forces and different historical, cultural, and social factors, which have been considered as dimensions of resilience against floods and have been emphasized in this study. Measures of solidarity are regarded as factors influencing citizens' commitment, responsibility, and participation in environmental psychology $[99,115]$. In environmental psychology, place is a linking and solidifying factor. Thus, a higher level of place attachment means a higher level of participation and increases citizens' participation at times of crises [99]. In a megacity such as Tehran, due to its geographical expansion and existence of social and cultural distance among districts [89,116,117], "readiness and communication actions of citizens and areas" becomes more determinant. In such areas, local solidarity can be created by reducing cultural discrepancies and creating multi-cultural bonds.

Access to different resources is critical in crisis management [118-120]. Additionally, the existence and sufficiency of health and hygienic resources is also critical because most crises cause damage to people's mental and physical health. Social resources such as NGOs and active civil institutions can also help to manage floods more effectively. Additionally, at times of crises, due to the aggravation of psychological distress and the dire need of citizens for better management of stress and anxiety [121-125], psychological sources become more determinant.

Economy is one of the main axes of sustainable development that is used to exploit environmental resources [126]. It plays a key role in planning, goal setting, and providing suitable conditions to achieve intended purposes. In the contemporary world, in which commodities and services need financial and monetary supports for production and movement, economy and fiscal capability is of great importance for governments and organizations to offer better services and make correct decisions.

In recent decades, the remarkable influx of people to Tehran and the mismatch between the growth of economic infrastructures and the growth of the city's population has led to many problems, including but not limited to unstable livelihoods, housing shortages, inadequate hygienic services, and unemployment, all of which affect economic resilience. In addition, dependence on the single-product economy and the lack of diversity in economic activities are among the main problems facing Iranian cities, including Tehran. The USled economic sanctions against the country have exacerbated this situation. This study found that the three factors of "empowerment", "flexibility", and "credit" play a key role in making Tehran economically resilient to floods. The presence of powerful economic activists such as citizens who are financially well-off and the presence of dynamic and active capacities was identified as factor of economic resilience to floods. A significant proportion of Tehran's population is suburban. This implies a lack of financial capabilities and, consequently, their vulnerability to various crises such as floods.

Economy and its pertinent elements have a role in the resilience of societies against crises and threats. There is, in fact, a bilateral relationship between economy and natural disasters. To be more specific, a dynamic and powerful economy can increase the resilience of society against crises, and in reverse, crises can damage the economy and disrupt economic growth and development $[127,128]$. The participants of this study hinted to the economic capabilities of society as a factor of resilience against natural crises such as floods. Citizens' financial capability, as an economic element to manage crises such as floods, can increase their adaptability capacity against damages [129,130]. Generally, "citizens" financial capability" is closely related to the presence of dynamic economic resources and "active economy" in the area [120,131,132].

Additionally, economic empowerment is associated with social equities and equal opportunities in society. In neoliberalism economic structures, money and economic 
capability are taken as a factor to expansion of social inequities and poverty [133-135] and can prevent different social groups from development and progress. In a large society like Tehran, with many people who are unemployed and lack relative welfare, it is conceivable to expect that distribution of opportunities was not equal and fair. A remarkable rate of people in this city live in slums and urban suburbs [136-138] that have the least facilities and equipment to deal with crises such as floods. In a study, Movahed et al. (2016) concluded that out of 6001 urban blocks in Tehran, 4361 blocks (72.6\%) are blocks where poor or very poor people live. Similarly, according to the governor of Tehran, $23 \%$ of the country's marginalized population lives in Tehran.Thus, creating necessary chances and possibilities to grow and train people's capabilities will be an effective factor to empower them against crises.

Intimes of disaster, many people might lose their job and income. Thus, returning them to normal conditions requires support and rehabilitation. Experiences from previous disasters show that crises often occur in urban suburbs with vulnerable and informal jobs $[139,140]$ whose business activities are not registered in any official institution and are not accountable to any institution.

In these areas, not only the structure of buildings and residential places may be damaged, but also many jobs and stores are shut and damaged. Thus, special attention should be paid to reopen stores and reactivate jobs so that people can meet their livelihood needs.

In extensive natural disasters, management is carried out by different institutions and organizations. Experience of severe disasters such as the destructive earthquake of Kermanshah province in November 2016 and also destructive floods in Fars, Golestan, Mazandaran, Lorestan, and Khoozestan provinces in April 2020 have indicated that crisis management has always faced numerous challenges, largely due to issues that arise from the macro-structures of society or issues that are relevant at the non-structural and micro levels [141,142].

Structural and performance problems in responsible organizations of crisis management are related to factors such as inefficiency of rules, lack of operational instructions, and lack of adequate cooperation and collaboration in performance methods among organizations [122,143,144]. Since institutions determine the rules of the game through the interaction of environment and society, organizational structures that have specific clear rules and can cooperate well with other responsible agents are more successful in crisis management [86,145-148].

The adaptation of rules with new conditions, improvement, correctness, and modifications are institutional measures that can be accomplished to ensure success in achieving intended goals $[149,150]$. Rules need to be in line with development actions, urban changes, and the general needs of society [151-154].

Interaction of public groups and responsible organizations is critical for resilience against crises. Using public forces and groups in all programs and measures leads to faster and more effective outcomes $[85,155,156]$. A lack of consistency of public groups and non-governmental organizations and also a lack of a specific method for attraction, organization, and participation of people are among the challenges of people-based groups at times of disaster [157-159]. Additionally, the interaction of officials with local businesses is also principal. As it was already pointed out, local businesses are among the most vulnerable centers at times of crises and the interaction of officials with these businesses can substantially help to mitigate damages in this domain.

Weaknesses in foresight and lack of planning by managers and officials have also been observed in the crisis management domain [160-162]. Dealing with crises requires a foresight approach by which correct predictions based on scientific precepts can be made $[160,161,163,164]$. However, a lack of such attitudes means that fulfilled measures are not often consistent with occurred disasters and crises. For example, in floods that have happened recently, it was noticed that waterways should be always dredged so that turbulent floods have a path for depletion. Unfortunately, however, measures such as building parks, roads, green spaces, and railways have closed these waterways. Thus, 
compiling foresight and effective and comprehensive programs can substantially reduce the probability of such crises and events in the future.

In addition to having technical knowledge, managers should be adequately motivated and aware to make effective decisions and changes while managing crises. In other words, managers should enhance the culture of responsibility and accountability in themselves and also their personnel. Managers and agents should have updated knowledge about crisis management. This can be realized through educational and cultural programs.

Research, as an effective way of informing, plays a key role in the executive and management ability of informal organizations and groups. Effective measures to manage flood disasters need updated knowledge which can be acquired through research. Research, in itself, needs financial and institutional support. These organizations should also have the chance to make use of other organizations' data and documents through sharing their information and findings with one another. The degree of managers' intention to learn from previous floods, collecting the history of floods, reviewing the programs pertinent to previous floods, comparing the previous and present management programs, inviting veteran managers to use their experience, and running systems to assess the satisfaction of citizens with the measures taken in previous and future floods are among strategies that the participants have highlighted as ways to gain experience by managers.

\section{Conclusions}

Despite the existence of various resilience-related analyses and models, there is no one-size-fits-all formula and guideline to which all sectors and communities can adhere, as resilience is a multidimensional concept within a complicated system consisting of economic, social, institutional, environmental, and ecological factors. Indeed, to arrive at a correct understanding of resilience, it is essential to consider the specific characteristics of the area. In the present study, an attempt has been made to identify and develop the standards and indices for assessing flood resilience based on Iranian experts' opinions.

The existence of many rivers in Tehran has exposed the city to the risk of flooding. This risk is even more serious in the western mountainous areas of Tehran. In recent decades, Tehran has become the destination of many citizens from villages and small towns, mainly due to the unbalanced accumulation of industries and more job opportunities. This in turn has not only increased the vulnerability of the city but also the unemployed population, non-standard buildings, and social problems. Since one main factor of managing natural crises is the preparedness to deal with them as well as the resilience level of cities, the present study aimed to propose a consistent and purposeful framework to assess Tehran's resilience. This framework can be used in the context of other megacities, especially those in Asia, as they are similar to Tehran.

As the results of the study show, resilience has several closely related facets. In other words, to deal with crises, cities need to have the necessary economic, social, and institutional capacities. In urban systems, the different components should interact well. This interaction should also exist between people and urban systems.

A city can be considered economically resilient only if it has economic innovation and production capacities. Stable economic infrastructures and a skilled workforce are characteristics of a resilient city. Adequate distribution of economic opportunities is also a key to economic growth as it not only increases economic performance but also enhances social participation and capabilities. Moreover, flexibility and the ability to return to the previous equilibrium or create a second equilibrium are among the characteristics of economic resilience. Flexibility increases the capacity of risk management in natural crises. To strengthen this capacity, supporting actors, especially supporting organizations such as insurance companies, are of great importance. A major obstacle in crisis management of major cities like Tehran is the lack of a sufficient budget and credit to support and provide adequate facilities to better cope with crises. This study has shown that sufficient budget and credit is another effective factor for economic resilience. 
As mentioned earlier, the interaction of human and urban systems is a facet of resilient systems. Humans, as active and conscious actors, play a role in managing urban crises and building resilience to risks. Therefore, it is essential to pay special attention to the social structures of any society as an aspect of resilience. Social resilience deals with the dynamic system of human interaction with the environment. Kinship and family relationships can thus be used to better monitor affairs in times of disasters.

Drawing on local traditions, skills, facilities, and customs can remarkably influence crisis management, provided that participation is accompanied by trust. Social capital is utilized in the form of social participation only when there is mutual trust between social activists and social and organizational actors. Mutual trust can provide shared and sympathetic capacity and cooperation between different agents in times of disasters. This in turn increases the likelihood of better crisis management. Another aspect of social resilience is the general attitude of society towards floods. Superstition and traditional beliefs such as fatalism may cause some citizens to not take crises such as floods seriously. In addition, a lack of learning from previous events, misunderstanding of the causes of crises, insensitivity to the seriousness of the disaster, and lack of adherence to rules and instructions are among the prevalent problems in damaged areas. However, it is relevant to mention that citizens' attitudes are highly dependent on their satisfaction with their government's policies and programs.

When social sources are present along with social solidarity, the social capacity to prevent and handle crises is expected to increase. As Tehran is a cultural melting pot, factors such as cultural and ethnographic beliefs, low social trust, and lack of constructive relations between cultures can be considered as barriers to social participation and solidarity, which are determinant in times of disaster. Cultural diversity, then, would only work to their advantage if it brought about social solidarity.

Institutional resilience is another facet. Institutions act as behavioral models and offer instructions on putting society's potential capabilities into action. Any institutional inadequacy in crisis management can lead to serious problems for the organizations charged with crisis management. These inadequacies may be due to poorly thoughtout rules, a lack of instructions for action, or poor cooperation between the groups and institutions involved. Rules related to the prevention and management of risks play a crucial role in building resilience capacity against floods. The absence, weakness, or inefficiency of rules have always proven a daunting challenge in the crisis management system. The inadequate monitoring of these rules and the incompatibility of the rules with the needs of society can lead to gross inadequacy in the response of organizations to crises. Therefore, it is relevant to continuously review the city rules to identify their weaknesses and strengths. In addition, punitive and motivational measures should be considered when necessary to ensure that rules are properly followed. Finally, the performance of related organizations should also be continuously reviewed and evaluated.

Institutional and organizational measures are only effective if, first, there is constructive cooperation between the related groups and, second, these groups actively engage with social forces. The relationship between organizations will be only effective if the tasks of each group and organization are clear and the necessary conditions for the fulfillment of their tasks are provided. Joint organizational interactions need common leadership and goals.

Institutional groups should have knowledgeable and capable individuals who have leadership skills to carry out rules as well as extensive knowledge of their position and role. Appropriate organizational culture and leaders' belief in flexibility and change are also factors for better management of crises. The staff needs to be trained unceasingly and their information should be updated according to needs. Since these organizations have common goals, the process of sharing information among them should be easy and smooth so that they can cooperate well. In addition, issues such as the appreciation of scientific knowledge and experts' attitude, the sharing of knowledge and expertise, and the use of experience are factors that create resilience to floods. 
Since the present study was an exploratory study, the main basis of the findings was the results of interviews with experts, which limits the possibility of explaining the findings based on previous theoretical and experimental models, which is a suggested route to take in future research. Moreover, by conducting field studies, the findings of the present study can be tested empirically and objectively, and the limitations of the analyzes on qualitative and subjective information can be removed.

Another limitation of the present study is the focus on specific geographical areas; while comparing the findings of the present study with the findings of other geographical areas can provide a good explanation of geographical, climatic, and cultural differences, so can comparative studies and meta-analysis of studies. It is recommended to remove this restriction.

Author Contributions: Conceptualization, B.G., Z.S.S.Z. and A.S.; methodology, B.G., Z.S.S.Z. and A.S.; software, B.G.; validation, B.G.; formal analysis, B.G.; investigation, B.G.; resources, B.G. and A.S.; data curation, B.G.; writing-original draft preparation, B.G., Z.S.S.Z., H.M., M.B. and A.S.; writing-review and editing, B.G. and A.S.; visualization, B.G.; supervision, Z.S.S.Z. All authors have read and agreed to the published version of the manuscript.

Funding: This research received no external funding.

Institutional Review Board Statement: Not applicable.

Informed Consent Statement: Not applicable.

Data Availability Statement: The data presented in this study are available on request from the corresponding author. The data are not publicly available due to ongoing research activities.

Conflicts of Interest: The authors declared no potential conflict of interest with respect to the research, authorship, and/or publication of this article.

\section{References}

1. Sim, T.; Wang, D.; Han, Z. Assessing the Disaster Resilience of Megacities: The Case of Hong Kong. Sustainability 2018, 10, 1137. [CrossRef]

2. UN. World Urbanization Prospects; United Nations, Department of Economical and Social Affairs: New York, NY, USA, 2018.

3. Hernantes, J.; Maraña, P.; Gimenez, R.; Sarriegi, J.M.; Labaka, L. Towards resilient cities: A maturity model for operationalizing resilience. Cities 2019, 84, 96-103. [CrossRef]

4. Kundzewicz, Z. Climate change impacts on the hydrological cycle. Ecohydrol. Hydrobiol. 2008, 8, 195-203. [CrossRef]

5. Bertilsson, L.; Wiklund, K.; Tebaldi, I.D.M.; Rezende, O.M.; Veról, A.P.; Miguez, M.G. Urban flood resilience-A multi-criteria index to integrate flood resilience into urban planning. J. Hydrol. 2019, 573, 970-982. [CrossRef]

6. Shah, F.; Ranghieri, F. A Workbook on Planning for Urban Resilience in the Face of Disasters; The World Bank: Washington, DC, USA, 2012.

7. Avashia, V.; Garg, A. Implications of land use transitions and climate change on local flooding in urban areas: An assessment of 42 Indian cities. Land Use Policy 2020, 95, 104571. [CrossRef]

8. Behzadi, F.; Wasti, A.; Rahat, S.H.; Tracy, J.N.; Ray, P.A. Analysis of the climate change signal in Mexico City given disagreeing data sources and scattered projections. J. Hydrol. Reg. Stud. 2020, 27, 100662. [CrossRef]

9. Tyler, S.; Moench, M. A framework for urban climate resilience. Clim. Dev. 2012, 4, 311-326. [CrossRef]

10. Filho, W.L.; Balogun, A.-L.; Olayide, O.E.; Azeiteiro, U.M.; Ayal, D.Y.; Muñoz, P.D.C.; Nagy, G.J.; Bynoe, P.; Oguge, O.; Toamukum, N.Y.; et al. Assessing the impacts of climate change in cities and their adaptive capacity: Towards transformative approaches to climate change adaptation and poverty reduction in urban areas in a set of developing countries. Sci. Total Environ. 2019, 692, 1175-1190. [CrossRef]

11. Mearns, R.; Norton, A. New Frontiers of Social Policy Social Dimensions of Climate Change Equity and Vulnerability in a Warming World; The World Bank: Washington, DC, USA, 2010.

12. Lee, C.-H.; Lin, S.-H.; Kao, C.-L.; Hong, M.-Y.; Huang, P.-C.; Shih, C.-L.; Chuang, C.-C. Impact of climate change on disaster events in metropolitan cities -trend of disasters reported by Taiwan national medical response and preparedness system. Environ. Res. 2020, 183, 109186. [CrossRef] [PubMed]

13. Rosenzweig, C.; Solecki, W.; Lankao, P.R.; Mehrotra, S.; Dhakal, S.; Ibrahim, S. Climate Change and Cities: Second Assessment Report of the Urban Climate Change Research Network; Cambridge University Press: Cambridge, MA, USA, 2018.

14. Bulkeley, H. Cities and Climate Change, 1st ed.; Routledge: London, UK, 2013.

15. Incropera, F. Climate Change: A Wicked Problem (Complexity and Uncertainty at the Intersection of Science, Economics, Politics, and Human Behavior), 1st ed.; Cambridge University Press: Cambridge, MA, USA, 2015. 
16. Peters, K.E. Living with the wicked problem of climate change. Zygon 2018, 53, 427-442. [CrossRef]

17. Sun, J.; Yang, K. The Wicked Problem of Climate Change: A New Approach Based on Social Mess and Fragmentation. Sustainability 2016, 8, 1312. [CrossRef]

18. Ghasemzadeh, B.; Sharifi, A. Modeling and Analysis of Barriers to Climate Change Adaptation in Tehran. Climate 2020, 8, 104. [CrossRef]

19. Radmehr, A.; Araghinejad, S. Developing Strategies for Urban Flood Management of Tehran City Using SMCDM and ANN. J. Comput. Civ. Eng. 2014, 28, 05014006. [CrossRef]

20. Samimi, S.; Ebrahimnejad, S.; Mojtahedi, M. Analysis of the susceptibility of interdependent infrastructures using fuzzy inputoutput inoperability model: The case of flood hazards in Tehran. Nat. Hazards 2019, 100, 69-88. [CrossRef]

21. Ghahroudi, M.T. Application of urban flood comprehensive model in megacities (Case study: North Eastern of Tehran). J. Urban Ecol. Res. 2009, 2009, 167-178.

22. Hasani, N. An Introduction to Compiling Operational Program of Flood Crisis Management; Ministry of Power Quarterly, No. 160. Tehran; Ministry of Power Publications, Water and Waste Water Affairs Deputy: Tehran, Iran, 2016.

23. Torabi, S. Watercourses Conditions and Fulfilled Measures to Prevent and Mitigate Damages at Time of Flood in Tehran; Tehran City Planning and Studies Center: Tehran, Iran, 2019.

24. Vitale, C.; Meijerink, S.; Moccia, F.D.; Ache, P. Urban flood resilience, a discursive-institutional analysis of planning practices in the Metropolitan City of Milan. Land Use Policy 2020, 95, 104575. [CrossRef]

25. Dwirahmadi, F.; Rutherford, S.; Phung, D.; Chu, C. Understanding the Operational Concept of a Flood-Resilient Urban Community in Jakarta, Indonesia, from the Perspectives of Disaster Risk Reduction, Climate Change Adaptation and Development Agencies. Int. J. Environ. Res. Public Health 2019, 16, 3993. [CrossRef]

26. Ghazanfarpour, H.; Kish, M.S.; Damaneh, M.S.; Goraghani, Y.S. On the Evaluation of the Reaction of Urban Managers Facing Flood as an Environmental Hazard with Emphasis on Resiliency (Case Study: Jiroft city). Geogr. Sustain. Environ. 2019, 9, 107-127. [CrossRef]

27. Laurien, F.; Hochrainer-Stigler, S.; Keating, A.; Campbell, K.; Mechler, R.; Czajkowski, J. A typology of community flood resilience. Reg. Environ. Chang. 2020, 20,1-14. [CrossRef]

28. Liao, K.-H. A Theory on Urban Resilience to Floods-A Basis for Alternative Planning Practices. Ecol. Soc. 2012, 17. [CrossRef]

29. Disse, M.; Johnson, T.; Leandro, J.; Hartmann, T. Exploring the relation between flood risk management and flood resilience. Water Secur. 2020, 9, 100059. [CrossRef]

30. Kuang, D.; Liao, K.-H. Learning from Floods: Linking flood experience and flood resilience. J. Environ. Manag. 2020, $271,111025$. [CrossRef] [PubMed]

31. Pizzo, B. Problematizing resilience: Implications for planning theory and practice. Cities 2015, 43, 133-140. [CrossRef]

32. Meerow, S.; Newell, J.; Stults, M. Defining urban resilience: A review. Landsc. Urban Plan. 2016, 147, 38-49. [CrossRef]

33. Meerow, S.; Newell, J.P. Urban resilience for whom, what, when, where, and why? Urban Geogr. 2019, 40, 309-329. [CrossRef]

34. Huck, A.; Monstadt, J.; Driessen, P. Building urban and infrastructure resilience through connectivity: An institutional perspective on disaster risk management in Christchurch, New Zealand. Cities 2020, 98, 102573. [CrossRef]

35. Leichenko, R. Climate change and urban resilience. Curr. Opin. Environ. Sustain. 2011, 3, 164-168. [CrossRef]

36. Ghasemzadeh, B. Exploring the Dimensions of Urban Climate Resilience Assessment: A Case Study of Tehran; Islamic Azad University Science and Research Branch: Tehran, Iran, 2020.

37. Sharifi, A. Resilient urban forms: A macro-scale analysis. Cities 2019, 85, 1-14. [CrossRef]

38. Ruszczyk, H.A. Ambivalence towards discourse of disaster resilience. Disasters 2019, 43, 818-839. [CrossRef] [PubMed]

39. Sharifi, A.; Chelleri, L.; Fox-Lent, C.; Grafakos, S.; Pathak, M.; Olazabal, M.; Moloney, S.; Yumagulova, L.; Yamagata, Y. Conceptualizing Dimensions and Characteristics of Urban Resilience: Insights from a Co-Design Process. Sustainability 2017, 9, 1032. [CrossRef]

40. Sharifi, A.; Yamagata, Y. Resilient Urban Planning: Major Principles and Criteria. Energy Procedia 2014, 61, 1491-1495. [CrossRef]

41. Oladokun, V.O.; Montz, B.E. Towards measuring resilience of flood-prone communities: A conceptual framework. Nat. Hazards Earth Syst. Sci. 2019, 19, 1151-1165. [CrossRef]

42. Campbell, K.A.; Laurien, F.; Czajkowski, J.; Keating, A.; Hochrainer-Stigler, S.; Montgomery, M. First insights from the Flood Resilience Measurement Tool: A large-scale community flood resilience analysis. Int. J. Disaster Risk Reduct. 2019, 40, 101257. [CrossRef]

43. Moghadas, M.; Asadzadeh, A.; Vafeidis, A.; Fekete, A.; Kötter, T. A multi-criteria approach for assessing urban flood resilience in Tehran, Iran. Int. J. Disaster Risk Reduct. 2019, 35, 101069. [CrossRef]

44. Radmehr, A.; Araghinejad, S. Flood Vulnerability Analysis by Fuzzy Spatial Multi Criteria Decision Making. Water Resour. Manag. 2015, 29, 4427-4445. [CrossRef]

45. Tali, M.G.; Sarvati, R.; Sarrafi, M.; Pourmousavi, M.; Derafshi, K. Flood vulnerability assessment in Tehran city. J. Rescue Relief 2012, 4, 79-92.

46. Rafie, Y.; Behtash, M.F.; Aghababaie, M. Assessing the Flood Risk of Tehran City and Offering Management Strategies; Deputy of studies and Infrastructue affairs planning and master plan, Center of studies and planning of Tehran, Information Technology Management and Documents Center Publications: Tehran, Iran, 2016. 
47. Salehi, E.A.M.; Rafii, Y.; Behtash, F.M. Urban Flood Hazard Zonation Using GIS and Fuzzy-AHP Analysis (Case Study: Tehran City). J. Environ. Stud. 2013, 39, 179-188. [CrossRef]

48. Farnia, P.; Rajaei, E.; Hadadi, M.; Madadi, M.; Aghajani, J.; Ahmad, M.M.; Farnia, P.; Ghanavi, J.; Velayati, A.A. Outdoor air pollution affects tuberculosis development based on geographical information system modeling. Biomed. Biotechnol. Res. J. 2018, 2, 39. [CrossRef]

49. Elo, S.; Kyngäs, H. The qualitative content analysis process. J. Adv. Nurs. 2008, 62, 107-115. [CrossRef] [PubMed]

50. Creswell, J. Qualitative Inquiry and Research Design: Choosing among Five Approaches; Sage Publications: London, UK, 2013.

51. Tesch, R. Qualitative Research: Analysis Types and Software; Routledge: London, UK, 2013.

52. Hsieh, H.-F.; Shannon, S.E. Three approaches to qualitative content analysis. Qual. Health Res. 2005, 15, 1277-1288. [CrossRef]

53. Egan, T.M. Grounded Theory Research and Theory Building. Adv. Dev. Hum. Resour. 2002, 4, 277-295. [CrossRef]

54. Speziale, H. Qualitative Research in Nursing: Advancing the Humanistic Imperative, 5th ed.; Wolters Kluwer Health; Lippincott Williams \& Wilkins: Philadelphia, PA, USA, 2011.

55. Graneheim, U.; Lundman, B. Qualitative content analysis in nursing research: Concepts, procedures and measures to achieve trustworthiness. Nurse Educ. Today 2004, 24, 105-112. [CrossRef] [PubMed]

56. Mohammadpour, A. Assessing of quality in qualitative research: Principles and strategies of generalizability and validation. Soc. Sci. 2010, 17, 73-107.

57. Guba, E.G. Criteria for assessing the trustworthiness of naturalistic inquiries. Educ. Commun. Technol. 1981, 29, 75-91. [CrossRef]

58. Beck, C.T. Qualitative Research: The Evaluation of Its Credibility, Fittingness, and Auditability. West. J. Nurs. Res. 1993, 15, 263-266. [CrossRef] [PubMed]

59. Royse, D. Research Methods in Social Work, 5th ed.; Thomson Brooks/Cole: Boston, MA, USA, 2007.

60. Lincoln, Y.S. Emerging Criteria for Quality in Qualitative and Interpretive Research. Qual. Inq. 1995, 1, 275-289. [CrossRef]

61. Draper, P. Handbook of Qualitative Research, 2nd edition edited by Norman K. Denzin and Yvonna S. Lincoln. J. Adv. Nurs. 2008, 33, 847. [CrossRef]

62. Folke, C. Resilience: The emergence of a perspective for social-ecological systems analyses. Glob. Environ. Chang. 2006, 16, 253-267. [CrossRef]

63. Lebel, L.; Anderies, J.M.; Campbell, B.; Folke, C.; Hatfield-Dodds, S.; Hughes, T.; Wilson, J. Governance and the Capacity to Manage Resilience in Regional Social-Ecological Systems. Ecol. Soc. 2006, 11. [CrossRef]

64. Walker, B.H.; Anderies, J.M.; Kinzig, A.P.; Ryan, P. Exploring Resilience in Social-Ecological Systems Through Comparative Studies and Theory Development: Introduction to the Special Issue. Ecol. Soc. 2006, 11, 12. [CrossRef]

65. Wang, Y.-C.; Shen, J.-K.; Xiang, W.-N.; Wang, J.-Q. Identifying characteristics of resilient urban communities through a case study method. J. Urban Manag. 2018, 7, 141-151. [CrossRef]

66. Naeini, G.H.; Rabieifar, V. Comparative study of the environmental challenges in core areas, Medial and periphery cities (Case study: Two regions, eleven and twenty-two in Tehran). J. Environ. Stud. 2015, 41, 233-256. [CrossRef]

67. Yadollaahi, R.; Ghafariyanbahraman, M.; Alizadeh, M.; Khatibizadeh, M. Environmental Impact Assessment of Tehran Iran Khodro Factory (EIA). J. Environ. Sci. Technol. 2019, 21, 123-135. [CrossRef]

68. Noruzi, A.; Sarvar, R.; Mahdavihajilouie, M. Evaluation of Effective Social Components in Resilience of District 12 of Tehran. Geogr. Res. Q. J. 2018, 32, 86-104. [CrossRef]

69. Tabatabaei, S.S. An investigation of urban-environmental management in Tehran during three historical periods of Qajar, Pahlavi and post Islamic revolution. Sci. Res. Q. Geogr. Data 2014, 22, 69-74.

70. Aliakbari, A.; Akbari, M. Interpretive-Structural Modeling of the Factors that Affect the Viability of Tehran Metropolis. Spat. Plan. Modares Hum. Sci. 2017, 21, 1-31.

71. Amiri, M.; Pourmousavi, S.; Sadeghi, M. An Investigation into Social Harms Originating in Squatter Settlement in the District 19 of Tehran Municipality from Urban Managers' Perspective. J. Urban Econ. Manag. 2014, 2, 119-137.

72. Le Brocque, R.; De Young, A.; Montague, G.; Pocock, S.; March, S.; Triggell, N.; Rabaa, C.; Kenardy, J. Schools and Natural Disaster Recovery: The Unique and Vital Role That Teachers and Education Professionals Play in Ensuring the Mental Health of Students Following Natural Disasters. J. Psychol. Couns. Sch. 2016, 27, 1-23. [CrossRef]

73. Fujioka, T.; Sakakibara, Y. School education for disaster risk reduction in Japan after the 2011 Great East Japan Earthquake and Tsunami (GEJET). Terrae Didat. 2018, 14, 313-319. [CrossRef]

74. Johnson, V.A.; Ronan, K.; Johnston, D.; Peace, R. Implementing disaster preparedness education in New Zealand primary schools. Disaster Prev. Manag. Int. J. 2014, 23, 370-380. [CrossRef]

75. Shiwaku, K.; Fernandez, G. Chapter 3 Roles of School in Disaster Education. Community Environ. Disaster Risk Manag. 2011, 7, 45-75. [CrossRef]

76. Apronti, P.T.; Osamu, S.; Otsuki, K.; Kranjac-Berisavljevic, G. Education for Disaster Risk Reduction (DRR): Linking Theory with Practice in Ghana's Basic Schools. Sustainability 2015, 7, 9160-9186. [CrossRef]

77. Nazli, N.N.N.N.; Sipon, S.; Radzi, H.M. Analysis of Training Needs in Disaster Preparedness. Procedia Soc. Behav. Sci. 2014, 140, 576-580. [CrossRef]

78. Khorram-Manesh, A.; Lupesco, O.; Friedl, T.; Arnim, G.; Kaptan, K.; Djalali, A.R.; Foletti, M.; Ingrasia, P.L.; Ashkenazi, M.; Arculeo, C.; et al. Education in Disaster Management: What Do We Offer and What Do We Need? Proposing a New Global Program. Disaster Med. Public Health Prep. 2016, 10, 854-873. [CrossRef] [PubMed] 
79. Yari, A.; Parishan, M. Assessment of the role of education in risk reduction settlement against natural risk (Earthquake) The case study: Rural region of Qazvin County. J. Spat. Anal. Environ. Hazards 2017, 4, 49-62.

80. Sahni, P.; Dhameja, A.; Medury, U. Disaster Mitigation: Experiences and Reflections, 1st ed.; Prentice-Hall of India: Delhi, India, 2004.

81. Alamdari, S. Patterns and Attitudes in Disaster Management, 1st ed.; Boostan-e-Hamid: Qom, Iran, 2010.

82. Ghasemzadeh, A.; Nasiraie, H. Influencing public thoughts in crisis management through modern general communication. Media Manag. 2015, 10, 61-76.

83. Hobbi, H.; Imani, M.B. The Role of the Media in Engineering Public Opinion during Crises.Commun. Cris. Issue Fear 2014, 6, $7-15$.

84. Eivazi, M. Media Management and Engineering of People's Thinking. Libr. Inf. Sci. Res. 2009, 10, 251-270.

85. Mahdieh, O. Investigating the Effect of Public Participation on Crisis Management Performance. Disaster Prev. Manag. Knowl. 2020, 10, 126-141.

86. Jovanovic, A. Public Deliverable H2020 Project: Smart Resilience Indicators for Smart Critical Infrastructure D6.7-Views from Insurance about the Smart Resilience Project; European Virtual Institute for Integrated Risk Management: Stuttgart, Germany, 2019.

87. Gardiner, E.P.; Herring, D.D.; Fox, J.F. The U.S. Climate Resilience Toolkit: Evidence of progress. Clim. Chang. 2018, 153, 477-490. [CrossRef]

88. Mugavero, R.; Sabato, V.; Stallo, C. Territorial Security: Architectures, methodologies and integrated systems for the information management in multi-risk scenarios. In Proceedings of the 2012 IEEE First AESS European Conference on Satellite Telecommunications (ESTEL), Rome, Italy, 2-5 October 2012; pp. 1-5.

89. Sharifi, S.; Khoshnevisan, F. An Analysis of Ethno-Cultural Empathy Ability in Tehran Metropolis. Rahbor Farhang 2018, 11, 199-219.

90. Riazi, H. Social and Cultural Limits of Tehran, Spatial Inequality and Lack of Social Justice. J. Cult. Stud. Commun. 2016, 12, 39-75.

91. Shafia, S. Social Pathology of Informal District through Ethnography: District Sample: Shemiran-e-No; The Second National Convention on Iran Social Pathologies; Iranian Sociology Institution: Tehran, Iran, 2012.

92. Shafia, S. Informal Neighborhood Center Landscape (Case Study: Shemiran-e-Now Informal Neighborhood). Manzar 2018, 10, 44-55.

93. Veisi, A.; Keshavarz, A. Defining Structural Model of Public Participation in Diminishing the Hazards of Natural Disasters. J. Manag. Plan. Stud. 2011, 24, 79-102.

94. Pelling, M. The Vulnerability of Cities: Natural Disasters and Social Resilience; Earthscan Publications Ltd.: London, UK, 2003.

95. Jovita, H.D.; Nashir, H.; Mutiarin, D.; Moner, Y.; Nurmandi, A. Social capital and disasters: How does social capital shape post-disaster conditions in the Philippines? J. Hum. Behav. Soc. Environ. 2018, 29, 519-534. [CrossRef]

96. Aldrich, D.P.; Meyer, M.A. Social Capital and Community Resilience. Am. Behav. Sci. 2015, 59, 254-269. [CrossRef]

97. Dynes, R.R. The Importance of Social Capital in Disaster Response; University of Delaware: Newark, DE, USA, 2002.

98. Renschler, C.S.; Frazier, A.; Arendt, L.; Cimellaro, G.P.; Reinhorn, A.M.; Bruneau, M. Developing the 'PEOPLES' Resilience Framework for Defining and Measuring Disaster Resilience at the Community Scale. 2010, pp. 1152-1161. Available online: https:/ / asu.pure.elsevier.com/en/publications/developing-the-peoples-resilience-framework-for-defining-and-meas (accessed on 17 January 2021).

99. Norris, F.H.; Stevens, S.P.; Pfefferbaum, B.; Wyche, K.F.; Pfefferbaum, R.L. Community Resilience as a Metaphor, Theory, Set of Capacities, and Strategy for Disaster Readiness. Am. J. Community Psychol. 2008, 41, 127-150. [CrossRef]

100. Benson, C.; Twigg, J.; Myers, M. NGO Initiatives in Risk Reduction: An Overview. Disasters 2001, 25, 199-215. [CrossRef]

101. Social Capital: Summing Up the Debate on a Conceptual Tool of Comparative Politics and Public Policy on JSTOR. Available online: https: / / www.jstor.org/stable/25741377?seq=1 (accessed on 13 January 2021).

102. Shimada, G. The role of social capital after disasters: An empirical study of Japan based on Time-Series-Cross-Section (TSCS) data from 1981 to 2012. Int. J. Disaster Risk Reduct. 2015, 14, 388-394. [CrossRef]

103. Kang, S.H.; Skidmore, M. The Effects of Natural Disasters on Social Trust: Evidence from South Korea. Sustainability 2018, 10, 2973. [CrossRef]

104. Nakagawa, Y.; Shaw, R. Social Capital: A Missing Link to Disaster Recovery. Int. J. Mass Emerg. Dis. 2004, 22, 5-34.

105. Lang, J. Creating Architectural Theory: The Role of the Behavioral Sciences in Environmental Design, 1st ed.; Van Nostrand Reinhold: New York, NY, USA, 1987.

106. Lang, J. Designing for Human Behavior, 1st ed.; Hutchinson \& Ross: Stroudsburg, PA, USA, 1980.

107. Bell, M.; Ashwood, L. An Invitation to Environmental Sociology; SAGE Publications: London, UK, 2015.

108. Steg, L.; Berg, A.; de Groot, J. Environmental Psychology: An Introduction, 2nd ed.; Wiley-Blackwell: Hoboken, NJ, USA, 2012.

109. Steg, L.; de Groot, J. Environmental values. In The Oxford Handbook of Environmental and Conservation Psychology, 1st ed.; Oxford University Press: New York, NY, USA, 2012.

110. Ruiu, G. Is Fatalism a Cultural Belief? An Empirical Analysis on the Origin of Fatalistic Tendencies; University of Cassino: Cassino, Italy, 2012.

111. Acevedo, G.A. Islamic Fatalism and the Clash of Civilizations: An Appraisal of a Contentious and Dubious Theory. Soc. Forces 2008, 86, 1711-1752. [CrossRef]

112. Paradise, T.R. Perception of earthquake risk in Agadir, Morocco: A case study from a Muslim community. Environ. Hazards 2005, 6, 167-180. [CrossRef] 
113. Baytiyeh, H.; Öcal, A. High school students' perceptions of earthquake disaster: A comparative study of Lebanon and Turkey. Int. J. Disaster Risk Reduct. 2016, 18, 56-63. [CrossRef]

114. Yari, A.; Zarezadeh, Y.; Ostadtaghizadeh, A. Prevalence of Fatalistic Attitudes toward Earthquake Disaster Risk Management in Citizens of Tehran, Iran. Int. J. Disaster Risk Reduct. 2019, 38, 101181. [CrossRef]

115. Soleimani, A.; Nohegar, A.; Salehi, E. Effects of Place Attachment Component's on Social Participation in Environmental Protection (Case study: Region one of Tehran municipality). J. Environ. Sci. Stud. 2019, 4, 1013-1020.

116. Tavana, M.; Nourian, F. Assessment of Social Sustainability in Sprawl Urban Neighborhoods (Case Study: Shadabad, Tehran). Hum. Geogr. Res. 2017, 49, 885-900.

117. Public Culture Council. Plan of Assessing and Measuring the Country's General Culture Indexes; Reports of Plans and Megacities Progress; Iran General Culture Council: Qom, Iran, 2010.

118. Moser, C.O.N. Asset-Based Approaches to Poverty Reduction in a Globalized Context AnIntroduction to Asset Accumulation Policy and Summary of Workshop Findings; The Brookings Institution: Washington, DC, USA, 2006.

119. Miles, S.B.; Chang, S.E. ResilUS: A Community Based Disaster Resilience Model. Cartogr. Geogr. Inf. Sci. 2011, 38, 36-51. [CrossRef]

120. Asadzadeh, A. Conceptualizing the Concept of Disaster Resilience: A Hybrid Approach in the Context of Earthquake Hazard. Universitäts- und Landesbibliothek Bonn, May 2017. Available online: https://bonndoc.ulb.uni-bonn.de/xmlui/handle/20.500 .11811/7022 (accessed on 16 January 2021).

121. Montazeri, A.; Baradaran, H.R.; Omidvari, S.; Azin, S.A.; Ebadi, M.; Garmaroudi, G.; Harirchi, A.M.; Shariati, M. Psychological distress among Bam earthquake survivors in Iran: A population-based study. BMC Public Health 2005, 5, 4. [CrossRef]

122. Asgarizadeh; Gharaie, S.M.N.; Zohour, M. Planning of Environmental Risks and Disasters Management in Line with Sustainable Development; Planning of Environmental Risks and Disasters Management in Line with Sustainable Development. Proceedings of the Fourth International Congress of Islam World Geographists; University of Sistan and Baluchestan: Zahedan, Iran, 2010.

123. Beaglehole, B.; Mulder, R.T.; Frampton, C.M.; Boden, J.M.; Newton-Howes, G.; Bell, C.J. Psychological distress and psychiatric disorder after natural disasters: Systematic review and meta-analysis. Br. J. Psychiatry 2018, 213, 716-722. [CrossRef]

124. Makwana, N. Disaster and its impact on mental health: A narrative review. J. Fam. Med. Prim. Care 2019, 8, 3090-3095. [CrossRef]

125. Parsizadeh, F.; Eskandari, M. Capabilities and needs of women in disaster-Case study of Bam earthquake. Res. Bull. IIEES 2013, $16,59-72$.

126. Goodland, R.; Ledec, G. Environmental management in sustainable economic development. Impact Assess. 1986, 5, 50-81. [CrossRef]

127. Oliva, S.; Lazzeretti, L. Measuring the economic resilience of natural disasters: An analysis of major earthquakes in Japan. City Cult. Soc. 2018, 15, 53-59. [CrossRef]

128. Xie, W.; Rose, A.; Li, S.; He, J.; Li, N.; Ali, T. Dynamic Economic Resilience and Economic Recovery from Disasters: A Quantitative Assessment. Risk Anal. 2018, 38, 1306-1318. [CrossRef] [PubMed]

129. Pfefferbaum, B.; Reissman, D.B.; Pfefferbaum, R.L.; Klomp, R.W.; Gurwitch, R.H. Building Resilience to Mass Trauma Events. In Handbook of Injury and Violence Prevention; Springer: Berlin/Heidelberg, Germany, 2007; pp. 347-358.

130. Godschalk, D.R. Urban Hazard Mitigation: Creating Resilient Cities. Nat. Hazards Rev. 2003, 4, 136-143. [CrossRef]

131. Mayor, M.; Ramos, R. Regions and Economic Resilience: New Perspectives. Sustainability 2020, 12, 4693. [CrossRef]

132. Cutter, S.L.; Burton, C.G.; Emrich, C.T. Disaster Resilience Indicators for Benchmarking Baseline Conditions. J. Homel. Secur. Emerg. Manag. 2010, 7. [CrossRef]

133. Baradaran, M.; Ghaffari, G.R.; Zahedi, M.; Rabiei, A. Suburb Settlement: Sociological Analysis of Community Issues of Housing Policy and the Phenomenon of Informality (Case of Study: Mian Abad, Eslamshahr, Tehran). J. Soc. Probl. Iran 2017, 8, $209-231$.

134. Zangeneh, A.; Roustaei, S.; Saedi, S.; Ahadnezhad, M.; Karbasi, A. Comparative Study of Social, Economic, Cultural and Spatial Inequalities across Urban Neighborhoods. J. Disabil. Stud. 2014, 4, $23-32$.

135. Sobhani, H.; Maleki, B. Assessment of Economic Transition under Neoliberalism Teachings. J. Iran Econ. Essays 2009, 6, 33-60.

136. Bayat, B. Analysis of Crimes in the Suburb Areas of Tehran and its Consequences. Soc. Secur. Stud. 2015, 6, 1-20.

137. Amiri, R.S.; Khodaie, Z. Investigating the Consequences of Informal Settlements: A Case Study of Tehran. J. Soc. Probl. Iran 2010, $1,65-80$.

138. Ladan, A.; Shirsavar, H.R. Reasons for Suburbanization in Tehran Metropolis. Urban Manag. Stud. 2010, 1, 71-88.

139. Keppel, J.; Mckinnon, S.J.; Dominey-Howes, D.; Gorman-Murray, A.W.; Morris, S. The LGBTI Community in the 2011 Queensland Floods: Marginality, Vulnerability and Resilience. 2014. Available online: http:/ / ro.uow.edu.au/sspapers/3675 (accessed on 16 January 2021).

140. Pongponrat, K.; Ishii, K. Social vulnerability of marginalized people in times of disaster: Case of Thai women in Japan Tsunami 2011. Int. J. Disaster Risk Reduct. 2018, 27, 133-141. [CrossRef]

141. Ahrens, J.; Rudolph, P.M. The Importance of Governance in Risk Reduction and Disaster Management. J. Contingencies Crisis Manag. 2006, 14, 207-220. [CrossRef]

142. Deverell, E.; Olsson, E.-K. Organizational culture effects on strategy and adaptability in crisis management. Risk Manag. 2010, 12, 116-134. [CrossRef]

143. Huntjens, P.; Lebel, L.; Pahl-Wostl, C.; Camkin, J.; Schulze, R.; Kranz, N. Institutional design propositions for the governance of adaptation to climate change in the water sector. Glob. Environ. Chang. 2012, 22, 67-81. [CrossRef] 
144. Palttala, P.; Boano, C.; Lund, R.; Vos, M. Communication Gaps in Disaster Management: Perceptions by Experts from Governmental and Non-Governmental Organizations. J. Contingencies Crisis Manag. 2011, 20, 2-12. [CrossRef]

145. Gaillard, J.; Mercer, J. From knowledge to action. Prog. Hum. Geogr. 2012, 37, 93-114. [CrossRef]

146. Vorraber, W.; Lichtenegger, G.; Brugger, J.; Gojmerac, I.; Egly, M.; Panzenböck, K.; Exner, E.; Aschbacher, H.; Christian, M.; Voessner, S. Designing Information Systems to Facilitate Civil-Military Cooperation in Disaster Management. Int. J. Distrib. Syst. Technol. 2016, 7, 22-40. [CrossRef]

147. Djalante, R.; Lassa, S. Governing complexities and its implication on the Sendai Framework for Disaster Risk Reduction priority 2 on governance. Prog. Disaster Sci. 2019, 2, 100010. [CrossRef]

148. Parsons, M.; Glavac, S.; Hastings, P.; Marshall, G.; McGregor, J.; McNeill, J.; Morley, P.; Reeve, I.; Stayner, R. Top-down assessment of disaster resilience: A conceptual framework using coping and adaptive capacities. Int. J. Disaster Risk Reduct. 2016, 19, 1-11. [CrossRef]

149. Jourdan, E.; Strauss, D. Planning for Wicked Problems a Planner's Guide to Land Use Law; Routledge: New York, NY, USA, 2016.

150. Holling, C.S. Understanding the Complexity of Economic, Ecological, and Social Systems. Ecosystems 2001, 4, 390-405. [CrossRef]

151. Sarrafi, M.; Abdollahi, M. Analysis of the Concept of Citizenship and Evaluation of its Status in the Urban Laws, Regulations and Management. Hum. Geogr. Res. 2008, 41, 115-134.

152. Barati, N.; Heidari, F.; Fathi, M.S. Towards a Democratic Process in Urban Planning and Design; Assessing the Status of Citizens' Involvement in Urban Plans and Projects in Iran. Bagh Nazar 2019, 16, 5-20. [CrossRef]

153. Kamanroodi, M.; Begdili, M. A comparative study of the laws and urban development plans based on the principles of good urban governance Case study: Urban development plans of Tehran. Urban Stud. 2014, 3, 37-48.

154. Zadeh, A.S.; Far, M.B. The necessity to reform management of urban development in Tehran. Territory 2008, 5, 35-53.

155. Fallah, S.; Nejad, J.H. The Role of Non-Governmental Organizations in Disaster Management: A Case Study of Bam Earthquake, Iran. Shahid Sadoughi University of Medical Sciences. September 2018. Available online: http://jder.ssu.ac.ir (accessed on 13 January 2021).

156. Babakhani, F.; Nasab, M.Y.; Nouri, M. Important influential factors on people's tendency for voluntary participation during crisis. J. Emerg. Manag. 2014, 2, 5-13.

157. Saei, A.; Badri, S.; Kazemi, N.; Tajik, F. Analysis of Components Influencing the Women's Participation in Disaster Management Cycle in Tehran. J. Spat. Anal. Environ. Hazards 2014, 1, 13-28.

158. Jahangiri, K.; Izadkhah, Y.O.; Azin, S.; Jarvandi, F. Public Participation in Confronting Natural Disasters in Khuzestan Province: The Officials. J. Rescue Relief 2011, 2, 11-20.

159. Mirsendesi, S.; Amiri, A.; Hasani, H. Feasibility of people participation in crisis management of Tehran Probable Earthquacke. Crisis Manag. Emerg. Cond. 2015, 2015, 23.

160. Mofazali, A.S.; Jahangiri, K. Towards a customized foresight model on "disaster risk management" in developing countries. Foresight 2018, 20, 467-487. [CrossRef]

161. Jahangiri, K.; Eivazi, M.-R.; Mofazali, A.S. The role of Foresight in avoiding systematic failure of natural disaster risk management. Int. J. Disaster Risk Reduct. 2017, 21, 303-311. [CrossRef]

162. Coaffee, J.; O'Hare, P. Urban resilience and national security: The role for planning. Proc. Inst. Civ. Eng. Urban Des. Plan. 2008, 161, 173-182. [CrossRef]

163. Mohajer, K.F.; Givehchi, S.; Omidvar, B.; Khazaie, S. Futurology Approach in Responding Programs to Earthquacke in Urban Regions. In Proceedings of the First National Futurology Convention, Tehran, Iran, 17 June 2021.

164. Jahantigh, N. The Effect of Systemic Attitude on Futurological Use of Organizational Knowledge of Crisis Management. In Proceedings of the Sixth International Conference on Economy, Management, and Engineering Sciences, Brussels, Belgium, 16-17 April 2015. 